\title{
Apropiación territorial y construcción de identidad colectiva frente al despojo de recursos. El caso del geoparque mundial Mixteca Alta, Oaxaca, México
}

\section{Territorial appropiation and building a collective identity against eviction from communal land. The case of la mixteca alta World Geopark in Oaxaca, Mexico}

\section{EFrÉN Orozco López}

Universidad de Guadalajara efren.lopez@academicos.udg.mx (MÉXICO)

Recibido: 18.102018 Aceptado: 28.05.2020

\section{RESUMEN}

Una discusión reciente en México es la posesión territorial. Este artículo comprende cuatro apartados que discuten tal fenómeno. El primero refiere al despojo como proceso histórico que se da por la disputa de recursos naturales, se ejemplifican dos casos de México y se plantean a los geoparques mundiales como alternativas de apropiación territorial de comunidades originarias. El segundo analiza fundamentos de los geoparques, y su situación en Latinoamérica, especificando al Geoparque Mundial Mixteca Alta (GMA). El tercero aborda la Educación Popular como paradigma de análisis, enfatizando al taller como herramienta de reflexión y acción en temas como la defensa del territorio. finalmente se da cuenta de dos talleres realizados a guías del GMA y los resultados referentes a la apropiación territorial.

${ }^{1}$ Este artículo se basa en una ponencia presentada en el eje 2: "Acción colectiva, movimientos sociales, sociedad civil y participación," del VI Congreso Nacional de Ciencias Sociales Las ciencias y la agenda nacional organizado por el Consejo Mexicano de Ciencias Sociales, A.C, la Universidad Autónoma de San Luis Potosí y El Colegio de San Luis, A.C., Centro Cultural Universitario Bicentenario, San Luis Potosí SLP del 19 al 23 de marzo de 2018. 


\title{
PALABRAS CLAVE
}

Geoparque mundial, derechos indígenas, lucha indígena, alternativas.

\begin{abstract}
An actual discussion in Mexico has been the possession of land by the indigenous communities. The article is organized into four sections. The first refers to territorial evictions as a relevant historical process in Latin America due to the dispute over natural resources. In this same section the attention is focused in two cases of the activities developed in two mexican indigenous lands and the importance of the existence of geoparks as an alternative to land possession. The second section analyzes the characteristics of geoparks, their situation in Latin America, particularly in the case of the Mixtec World Geopark (GMA) in Mexico. The third part refers to methodologies that are based on Popular Education. It emphasizes the implementation of workshops as a tool that intends to generate reflection and action on issues such as the defense of the communal land. The final section represents the testimonies of two workshops conducted with GMA guides and their results regarding territorial management and property.
\end{abstract}

\section{KEY WORDS}

World Geopark, indigenous rights, Indigenous fight, alternatives.

\section{INTRODUCCIÓN}

En las últimas décadas la Educación Popular emanada del pensamiento del brasileño Paulo Freire, ha tenido un gran auge, generando e inspirando una diversidad de procesos encaminados al fortalecimiento de luchas sociales e iniciativas liberadoras de distintos tipos. Este marco de pensamiento, tanto de la propuesta freireana, como de los procesos de educación popular adaptados a circunstancias específicas, paulatinamente ha permeado en muchos espacios académicos, particularmente en el trabajo del cuidado medioambiental (Osorio y Contreras, 2009); su desarrollo implica una coordinación importante entre diversos actores sociales y compromisos ético-políticos que permitan la posibilidad de conciliación de intereses y el establecimiento de objetivos comunes (Abarca, 2016). Un campo fértil para la generación y desarrollo de procesos de educación popular, son las luchas por la defensa del territorio y del cuidado del medio ambiente por parte de colectivos sociales en conjunto con el concurso de profesionales académicos.

Un espacio emergente de protección del patrimonio geológico y valoración de culturas y conocimientos locales en donde coinciden académicos y pobla- 
ciones, es el proyecto Geoparques Mundiales Unesco (Carcavilla y García, $\mathrm{s} / \mathrm{f})$. Este mismo proyecto se erige como una plataforma de coincidencia entre procesos sociales diversos que permiten profundizar relaciones entre academia y comunidades en donde la investigación es negociada y construida colectivamente a partir de necesidades particulares de las comunidades como, por ejemplo, el mejoramiento de los suelos de cultivo, de la fertilización, la recuperación de conocimientos ancestrales en peligro de perderse, los procesos de organización y capacitación sobre la defensa del territorio; e intereses académicos como la visualización y análisis de procesos de lucha y resistencia social, la construcción de alternativas económicas, sociales y políticas, la manera tradicional de sembrar, las características particulares de ciertos productos agrícolas y los suelos en los que se producen.

En este sentido el Geoparque Mixteca Alta (GMA) en Oaxaca, México, se ha convertido en un espacio privilegiado de análisis y construcción de procesos de educación popular entre habitantes de nueve municipios indígenas e investigadores de diversos perfiles profesionales del Instituto de Geografía de la Universidad Nacional Autónoma de México (UNAM). En este artículo se privilegian procesos de investigación social enfocados en el trabajo con guías del GMA, que son personas de las mismas comunidades, que tienen como función acompañar los recorridos ofertados en su territorio. La problemática abordada se enmarca en la creciente tensión entre despojo territorial y la necesaria generación de alternativas de protección del territorio en el contexto latinoamericano, particularizando el caso de México.

Metodológicamente se aborda la perspectiva de la educación popular y como herramienta de obtención de información se privilegia al taller como instrumento de intervención y de construcción colectiva de conocimiento, desde el paradigma de la pedagogía de la liberación creada por el brasileño Paulo Freire (Carreño, 2010); algunos paradigmas teóricos que sustentan y robustecen la ruta metodológica son la territorialidad (Lara, 2016), la ecología política (Delgado, 2013 a; Leff, 2003) y la acumulación por desposesión (Harvey, 2005).

\section{DESPOJO TERRITORIAL}

El presente artículo reflexiona en torno a las resistencias indígenas, (Zmeke de Zonana, 2000; Guevara, 2009) y algunos de los procesos metodológicos que han emanado de la hermandad entre movimientos sociales e intelectuales. Latinoamérica, históricamente ha sido un campo de disputas por recursos naturales (Muñoz, 2013). Algunos autores plantean que la resistencia no es un concepto unidimensional, en todo caso es un fenómeno que aglutina amplios sectores sociales, abocado a la generación de alternativas en todos sentidos: sociales, culturales, económicas, rompiendo la normalización del status quo dominante (Roa, 2014). Es una esperanza con referentes prácticos que se concretan en la creación de procesos comunitarios enfocados en la reconstrucción y fortalecimiento del tejido social (Vázquez, 2005) y en contra del despojo territorial. 
La resistencia indígena se ha decantado por procesos de construcción de autonomía y discursos autonómicos, algunas veces a partir de modificaciones constitucionales, asociadas a tratados internacionales, otras de facto a partir de la insurrección, como el caso del Ejercito Zapatista de Liberación Nacional (EZLN) en México (Ortiz, 2004). El punto central de la construcción de las autonomías indígenas dentro de Estados nacionales es el ejercicio de la autonomía territorial; ésta acarrea tensiones entre grupos que construyen la autonomía y las legislaciones nacionales, que contemplan al territorio para planes no necesariamente concomitantes con las visiones autonomistas (González, 2010). En este contexto es fundamental la participación entre sectores académicos y sociales en la construcción de metodologías participativas emanadas de la educación popular encaminadas a la transformación de realidades desiguales y la aplicación de derechos reconocidos, pero no respetados.

Otros temas transversales para el análisis y la investigación que se han generado son los conflictos sociopolíticos y la territorialidad (Modonesi e Iglesias, 2016). Dentro de la territorialidad, destaca la apropiación territorial a partir de discursos que otorgan sentidos de pertenencia, significación y control sobre el territorio y su cuidado (Hernández y Furlan, 2016). En este sentido destacan ejemplos de pueblos originarios que han logrado negociar con el Estado para delimitar su territorialidad a partir de lugares sagrados, la memoria colectiva, o relatos míticos (Barabas, 2004).

En México, en años recientes se han documentado diversas fórmulas legalistas para el despojo de territorios de pueblos indígenas es las que, las piezas clave son los visitadores agrarios y los programas gubernamentales de regularización de tierra, impulsados a partir de la modificación del artículo 27 constitucional, como por ejemplo PROCEDE o PROCECOM (Torres, Fernández y Gómez, 2018). Estos programas son utilizados sistemáticamente para, de manera condicionada y vinculada con secretarías gubernamentales, "regularizar" y "delimitar" territorios comunitarios para volverlos de interés privado o por lo menos, alienable, beneficiando intereses empresariales, industrias, nacionales o internacionales e incluso, intereses de funcionarios públicos. En este sentido la organización comunitaria en procesos de construcción del tejido social a partir de la educación popular es de gran importancia para generar estrategias de defensa del territorio.

Algunos de los mecanismos más comunes de despojo territorial son el arrendamiento de tierras, - muchas veces sin consulta e información para los dueños del territorio -, la compra a partir de la coacción de las asambleas o de líderes y autoridades, la expropiación a partir de la denominación de áreas naturales protegidas (Torres, Fernández y Gómez, 2018; Martínez y Haro, 2015).

El informe sobre los derechos de los pueblos indígenas de México de la Organización de las Naciones Unidas, plantea que el régimen agrario actual no responde a las necesidades de los pueblos indígenas, tampoco se corresponde con las obligaciones adquiridas por el Estado mexicano con instancias internacionales; se plantea que la falta de una legislación adecuada para la protección al territorio donde habitan pueblos originarios es raíz de muchas de las violaciones de derechos humanos que se presentan actualmente (ONU, 2018). 
El objetivo del presente artículo se centra en la visualización de experiencias de apropiación territorial desde las comunidades (Aedo, 2008; Ramírez, González y Espinosa, 2014). En especial me enfoco en el caso de nueve municipios mixtecos de Oaxaca, México, que desde el año 2014 construyen el Geoparque Mundial Mixteca Alta (GMA), que fue avalado por la UNESCO en el año 2017. Me centro en la apropiación del territorio que han logrado los guías del GMA. En este sentido se ha planteado que la apropiación territorial es un proceso gradual y permanente, que implica tanto la apropiación de conocimientos y técnicas ajenas a las culturas locales, así como tres planos: el subjetivo que implica las representaciones sociales sobre el territorio, la dimensión concreta que tiene que ver con sus usos, y la dimensión normativa, que se relaciona con la regulación del territorio por quienes lo habitan (Márquez y Legorreta, 2017).

La apropiación territorial implica estrategias de orden jurídico, discursos fundamentados en la identidad étnica, discursos fundacionales, de parentesco, mítico-religiosos o estrategias de acción política (Lara, 2016). Con lo planteado se pretende mostrar la manera en la que los guías del GMA se apropian de su territorio a partir de diversas estrategias, como por ejemplo discursos subjetivos, apropiación de conocimientos a partir de su relación con académicos de la UNAM y estrategias de acción política para defender y construir su territorio a partir de la denominación y aval UNESCO del GMA.

La metodología se fundamenta en fuentes tanto primarias como secundarias. En las primarias se encuentra información de campo obtenida durante un periodo comprendido entre agosto y diciembre del 2017, en la que se cuenta la realización de ocho talleres dirigidos a guías, autoridades comunales y municipales de los municipios que integran el GMA. Dentro de estos talleres destacan dos que le dan sentido al artículo y que fueron dirigidos exclusivamente a guías y que se enfocaron a la defensa del territorio y la sistematización de experiencias. En este contexto pude percatarme de la importancia de trabajar con los guías, debido a que son actores clave en la configuración del GMA dada su posición de intermediarios entre comunidades, las autoridades de sus municipios y los académicos de la UNAM.

Las fuentes secundarias se relacionan con procesos metodológicos cualitativos (Quecedo y Castaño, 2002) emanados del contexto latinoamericano en donde, durante la segunda mitad del siglo XX se comenzaron a cuestionar viejos modelos metodológicos fundamentados en el positivismo, valorizando aportes desde procesos fenomenológicos y reforzándolos con la premisa de la participación de los pueblos en la construcción del conocimiento y en un posicionamiento ético político con los actores involucrados (Mejía, 2015). En este sentido la Pedagogía de la Liberación de Freire se convirtió en plataforma para generar procesos de educación popular (Bruno-Jofré, 2016) que poco a poco comenzaron a tener incidencia en ámbitos académicos.

La importancia de la visualización de experiencias de lucha indígena y construcción de metodologías participativas para la defensa del territorio radica en que se ha documentado que en México, en los últimos años un grupo particularmente vulnerable al despojo son los pueblos originarios. Particularmente 
el pueblo Cucapá de California se ha visto afectado desde 1993 debido a que su territorio fue designado como área natural protegida, por lo que su modo de vida ancestral, la pesca, ya no pudo ser reproducido. También los pueblos Yaqui, Yoreme, Mayo Pima, en Sonora, han sido despojados de su territorio a través de mediciones mal realizadas a partir de la aplicación del Programa de Certificación de Derechos Parcelarios y Titulación de Solares Urbanos (PROCEDE) (Martínez, 2008).

Debido al abandono que las instancias gubernamentales han tenido del sur de México y la cohesión comunitaria que se vive en estados como Chiapas, Guerrero o Oaxaca, así como al levantamiento del EZLN, los procesos de despojo han sido más lentos y difíciles de realizar que en el norte del país, pero no significa que no existan o se encuentren en proceso. En este sentido es necesaria la visualización de formas alternativas de entender el desarrollo y la construcción de nuevas maneras de lucha y resistencia indígena pacífica. De aquí la importancia de entender, también el potencial que el concepto de geoparques mundiales puede tener para la defensa y el cuidado del territorio, así como para la reconstrucción y/o fortalecimiento del tejido social, la reproducción de formas de vida otras que aporten nuevas fórmulas o fortalezcan las ya existentes de buen vivir para los pueblos originarios.

\section{LOS GEOPARQUES MUNDIALES}

El concepto geoparques mundiales de la UNESCO es un proyecto relativamente nuevo que se ha convertido en opción de sustentabilidad y cuidado del territorio para el siglo XXI. Las primeras ideas se presentaron a finales del siglo XX en el Congreso de Geología, en Beijing. Los países impulsores fueron Alemania, Francia Grecia y España fundamentados en la necesidad de potenciar comunidades rurales con problemas económicos, pero con potencial geológico, sin una categoría particular; en todo caso son espacios con diversidad social, agrícola, de producción, de conservación, muchos de ellos en contextos de población indígena (Fernández Da Silva, Morbeck De Oliveira y Ramos, 2016).

El concepto geoparques parte de un creciente interés por la valoración y cuidado del patrimonio geológico y su conexión con elementos culturales que dan cuenta de un funcionamiento holístico en una región determinada; también responden a un proceso de desarrollo de las ideas sobre la conservación a partir de la declaración de áreas naturales protegidas a finales del siglo XIX (Bahía de Aguiar et al., 2013).

Se parte de la concepción de parques nacionales protegidos que se enfocan a la preservación de la diversidad biológica. A mediados del siglo XX el concepto adquirió nuevos matices proponiéndose reservas de la biosfera que se fundamentan en la diversidad biológica, pero en su relación con el ser humano. En el último tercio del siglo XX esta apuesta de conservación se reforzó con la creación de la Convención del Patrimonio Mundial, impulsada por la UNESCO, y a principios del siglo XXI se concretó la Red Europea de Geoparques que 
rompió con el concepto tradicional de área protegida, planteando la posibilidad de que los habitantes de las comunidades implicadas en los proyectos manejen su territorio y generen alternativas productivas desde sus formas de vida y conocimientos (Sánchez, 2013).

Si bien el concepto de geoparque se originó en Europa, en continentes como el americano ofrece oportunidades para generar procesos alternativos de producción y de empoderamiento de poblaciones en situación de vulnerabilidad, debido a su potencial en el componente social y cultural. En Latinoamérica son espacios de oportunidad para revertir procesos de empobrecimiento, exclusión y discriminación enraizados estructuralmente. Se han evaluado algunos de los primeros intentos de implementación de geoparques en el continente americano (Sánchez, Arredondo et al 2014). La evaluación se realizó en 11 territorios comprendidos en cuatro países (Brasil, Chile Ecuador y México), a partir de los resultados se estableció que, con relación a aspectos geológicos y de biodiversidad, en los cuatro casos el componente de lo social adquirió menor calificación, por lo que existe la necesidad de generar y/o reforzar estrategias de comunicación, educación y desarrollo económico.

Dentro de los elementos sociales cobra relevancia trabajar en aspectos como la organización comunitaria, la apropiación de aprendizajes que coadyuven al fortalecimiento y mejoramiento de las prácticas de los actores involucrados, potenciar conocimientos locales para que adquieran una dimensión discursiva que permita generar procesos identitarios particulares que robustezcan una oferta enraizada en prácticas culturales, sociales y políticas; todo esto enmarcado en procesos metodológicos participativos. Estos elementos son los que, en última instancia le otorgan sentido a un geoparque, es decir, si bien el aspecto geológico es central para la exposición y manejo de la oferta turística, su vinculación con la vida cotidiana y la manera en que los pueblos han generado estrategias de revalorización de sus culturas y la reivindicación de sus luchas por cuidar y mantener sus territorios en el marco geológico de su contexto físico es muy relevante.

En otros estudios se destaca la implementación de procesos interdisciplinarios en donde participan, desde los pobladores del lugar, hasta geólogos, geógrafos, antropólogos, estudiantes y autoridades de diversos niveles, para elaborar y desarrollar estrategias conjuntas por el bien de las localidades. En estos procesos se definen y estudian espacios de interés geológico, biológico y cultural con potencial turístico, en donde se ofrecen desde panorámicas espectaculares, hasta espacios que llevan al pasado a través de pinturas rupestres. El geoparque también permite vincular los cambios geológicos con el desarrollo de las formas de vida de los lugares en cuestión (Carut et al, 2017; Schilling et al, 2015). Estos hallazgos se interpretan como una ruptura epistemológica que derivan en una nueva racionalidad donde dialogan aspectos científicos y culturales.

La importancia de los geoparques radica en que permiten la vinculación entre geopratrimonio y cooperación comunitaria a través de planes de conservación de espacios geológicamente valiosos amenazados por la implementación del turismo desordenado, o prácticas extractivas. Además, ofrece oportunidades para la elaboración de materiales educativos, el trazado de rutas y la vinculación con 
universidades que detonen procesos de fortalecimiento local con la participación directa de la población (Maestrocola, Salgado y Casadío, 2014) así como fortalecer procesos de investigación y de creación de metodologías participativas.

Un geoparque es una posibilidad turística con alcances no ceñidos a estándares homogéneos, brinda oportunidades epistemológicas y políticas en las que conocimientos locales se convierten en plataformas para la creación de turismo de conciencia y cuidado del territorio que coadyuven al fortalecimiento de la interculturalidad fundamentada en diálogos de saberes (Ishizawua y Rengifo, 2012) y de trabajo interinstitucional, donde la academia aterrice discursos colaborativos en prácticas concretas, fortaleciendo con esto las emergentes epistemologías del sur (Infante, 2013). Por esto es fundamental el trabajo participativo con actores involucrados en el geoparque, en este caso con guías del GMA. A partir de este trabajo es posible generar conocimientos co-elaborados, evidenciar y representar formas de saber que no necesariamente son reconocidas en las formas tradicionales de hacer turismo, y descubrir nuevas aristas de construcción y/o reconstrucción de tejido social que no necesariamente serán recetas para seguir, pero si inspiración para otros procesos.

\section{El Geoparque Mundial Mixteca Alta (GMA).}

En México existe una diversidad de espacios para ser considerados candidatos a convertirse en geoparques, y se han establecido lugares de difusión del conocimiento científico documentados e impulsados por diversas instituciones, como por ejemplo el Museo de Historia Natural de Cabo San Lucas, puesto en marcha por el Departamento de Geología Marina de la Universidad Autónoma de Baja California Sur. El Instituto de Medio Ambiente y Comunidades Humanas de la Universidad de Guadalajara identificó doce sitios potenciales para ser considerados patrimonio geológico; también existen espacios de interés geológico enclavados en zonas mineras no activas. La UNAM desde diversos espacios como el Instituto de Geografía o el de Geofísica participan en proyectos de valoración del geopatrimonio (Palacio, 2013).

En el marco de los geoparques existen tres experiencias que llevan su proceso más avanzado. El geoparque en el distrito minero Tlalpujahua-El Oro en los estados de México y Michoacán que se encuentra en espera de la acreditación UNESCO (Espinosa, 2016) y los geoparques Comarca Minera en $\mathrm{Hidalgo}^{2}$ y Mixteca Alta en Oaxaca, que ya cuentan con tal reconocimiento.

Con respecto al Geoparque Mundial Mixteca Alta, éste surgió en el año 2014 bajo la coordinación académica del Dr. José Luis Palacio de la UNAM. En el GMA convergen nueve municipios ${ }^{3}$ indígenas, algunos catalogados como

${ }^{2}$ La información sobre la Comarca Minera en Hidalgo se consultó el día 22 de octubre del 2017 en: http://geoparquehidalgo.com

3 Tonaltepec, Soyaltepec, Yucuita, Yanhuitlán, Chachoapam, Sinaxtla, Tillo, Topiltepec, San Juan Teposcolula

EMPIRIA. Revista de Metodología de Ciencias Sociales. N. ${ }^{4} 48$ septiembre-diciembre, pp. 67-93.

ISSN: 1139-5737, DOI/ empiria.48.2020.28071 
de muy alta marginación. El GMA ofrece paisajes erosivos que a lo largo de la historia han generado una relación estrecha con el desarrollo de la cultura mixteca y de los procesos productivos en la región. Desde la UNAM el trabajo en el geoparque se ha realizado con una perspectiva metodológica participativa e interdisciplinaria, lo que ha generado una relación estrecha entre académicos, autoridades y poblaciones involucradas (Rosado y Ramírez, 2017).

El GMA es un proceso social que involucra diversos actores que históricamente han interactuado en un territorio común, pero desde el año 2014 la figura del geoparque en la región mixteca de Oaxaca ha reconfigurado las relaciones. Esta región ha sido históricamente olvidada por las autoridades gubernamentales. En las comunidades indígenas regidas por sistemas políticos tradicionales denominados de "usos y costumbres" o más recientemente "Sistemas Normativos internos" (SNI), a diferencia de un cargo gubernamental, el trabajo o servicio como autoridad no necesariamente se compensa con una remuneración económica; en todo caso se finca en el prestigio y el servicio al pueblo. En este contexto, autoridades municipales que se encargan de la administración política, las de bienes comunales, que son las garantes del cuidado del territorio, los prestadores de servicios y los nuevos agentes emergentes como los guías del GMA, interactúan desde una nueva posición, y observan en el proceso de concreción del geoparque una oportunidad para desarrollarse como región.

La incursión de la UNAM en el marco del geoparque como institución académica, asesora en materia científica y en temáticas como la organización comunitaria, es visualizada por gran parte de la población que habita y participa del GMA como una oportunidad para poder generar nuevos procesos de desarrollo desde sus propios conocimientos y necesidades específicas. En este contexto complejo, profundizaré en el trabajo realizado con guías del GMA y su labor como intermediarios entre la UNAM y sus científicos que los forman en temáticas específicas, y las autoridades comunitarias, quienes llevan la administración y cuidado de su territorio.

La configuración del GMA se enmarca en escenarios globales en los que se entrelazan diversos procesos, muchas veces contradictorios. Desde espacios de lucha indígena (Orozco, 2015) por hacer valer derechos internacionales que se cruzan con reformas estructurales que favorecen el despojo del territorio a partir de la acumulación por desposesión (Harvey, 2005), hasta conflictos internos derivados de la descomposición del tejido social a partir del debilitamiento de instituciones tradicionales como la asamblea y el tequio y la incursión de los partidos políticos en espacios regidos por sistemas de "usos y costumbres" (Singer, 2013).

Los nuevos modelos de conservación fundamentados en una visión holística del territorio con participación directa y activa de sus pobladores, como los planteados desde la concepción de los geoparques, conviven con prácticas ancladas en el extractivismo, actividad que se fundamenta en la explotación intensiva de recursos naturales. Las principales actividades del extractivismo son la industria de la minería y los hidrocarburos. En este escenario el Estado garantiza políticas 
de protección de las necesidades del capital privado, muchas veces en detrimento de las poblaciones que habitan y protegen los territorios (Portillo, 2014).

En México se presentan procesos paradójicos en espacios que han sido denominados áreas protegidas y de conservación, y han sido cedidos para la explotación de recursos naturales a través de concesiones que benefician a empresas privadas. La privatización de la tierra, a pesar de la modificación del artículo 27, no se ha concretado del todo debido a la resistencia de grupos de ejidatarios y comuneros. Oaxaca cobra importancia debido a que en su territorio se disputan recursos como regiones terrestres prioritarias, regiones hidrológicas, montañas, bosques y recursos minerales (Sandoval, 2015). Desde esta perspectiva la implementación del GMA es un espacio de oportunidad para lograr coadyuvar en procesos de conservación y educación más allá del territorio comprendido en el propio geoparque y de lucha y resistencia por el territorio, que sin duda abonarán a encontrar nuevas formas pacíficas de construcción de autonomía indígena.

En nuestros días el despojo de territorios se presenta a partir de la fortaleza de los sectores privados frente al debilitamiento del Estado, lo que genera confrontaciones violentas entre pobladores que gozan de territorios ricos en recursos naturales y quienes pretenden hacerse de esos territorios a partir de políticas de compra y venta, o de expropiación fundamentada en planteamientos retóricos como "el bien de la nación" o "el bien común"; Casos de este tipo son: la masacre de Aguas Blancas en Oaxaca perpetrada en el marco de la protección de bienes naturales por parte de sus pobladores, el despojó a comunidades de sus territorios por parte de la minera canadiense "Álamos Gold" en Mulato Sonora, y el derrame de arsénico por parte de la minera "Media Luna" en Cocula, Guerrero, que provocó graves daños ambientales (Azamar y Ponce, 2014).

El auge que tiene en distintos países latinoamericanos el extractivismo responde a la necesidad de expansión de la acumulación del capital en pocas manos, lo cual lleva a una demanda por el control de nuevos territorios con potencial de explotación, pero también a la conformación de resistencias ante estos hechos. Desde esas resistencias o inspirados en ellas, se han generado modelos teóricos alternativos como por ejemplo la llamada ecología política que se conforma a manera de campo de estudio dedicado a la develación y reconocimiento de los juegos de poder involucrados en procesos de despojo, apropiación e industrialización de territorios en diferentes partes del mundo y su impacto en el medio ambiente (Delgado, 2013 a).

La ecología política es otra vertiente del pensamiento crítico que reflexiona en torno a la complejidad medioambiental que vivimos actualmente, en el entramado de las relaciones de poder entre individuo y mundo globalizado, donde está en juego la supervivencia en un contexto de apropiación de la naturaleza a partir de intereses dominantes. Esto lleva a un contexto de desigualdad que es enfrentado por movimientos sociales que cuestionan el deterioro ambiental y crean y/o adoptan formas alternativas de reapropiación de territorios (Leff, 2003).

Otras interpretaciones plantean que la ecología política puede considerarse como un campo de reflexión y construcción de conocimiento interdisciplinario 
centrado en el análisis de los efectos nocivos de ciertas tecnologías y la generación de desechos que comprometen el equilibrio de los procesos ecológicos que están siendo llevados a niveles extremos. En este sentido la ecología política se ha convertido en una herramienta teórico-práctica para el análisis y la incidencia en América Latina debido a la calidad de las resistencias emergentes y la voracidad de los grandes capitales en el continente (Delgado, 2013 b).

Otro paradigma teórico surgido desde la resistencia al despojo y frente al neocolonialismo es la llamada necropolítca (Mbembe, 2011). Algunos elementos que la componen son: el ejercicio de la autoridad mediante la violencia, la concepción del ser humano como "remplazable-despojable", el establecimiento de la soberanía a través de la autoadjudicación del derecho a hacer la guerra, el entendimiento de la política como procedimiento técnico y la territorialización que implica la producción de líneas de demarcación a partir de criterios jerárquicos, que responden a intenciones de extracción de recursos.

La necropolítica se encuentra estrechamente relacionada con las guerras del territorio en donde la generación de escasez y la manipulación son herramientas de apropiación de riquezas naturales y de instauración de jerarquías de poder. Este despojo del territorio se extiende al despojo de significados y prácticas culturales como visiones del mundo y relaciones con el entorno (Ceceña, 2017).

En el contexto del GMA se ha presentado un caso que se podría enmarcar en este universo analítico: Durante el mes de agosto del 2017 en el municipio de Yucuita los habitantes decidieron desconocer a sus autoridades y nombrar un nuevo cabildo a través de asamblea comunitaria. El hecho que detonó la situación fue que el presidente municipal destituido realizó convenios con una empresa coreana para que ésta pudiera instalarse. Hasta antes de los acontecimientos las autoridades de Yucuita no habían tenido participación directa en el geoparque, pero a partir de la destitución, las nuevas autoridades se involucraron de manera importante y según sus propias palabras: "El geoparque es un espacio que ayuda al cuidado y la protección del territorio 4 ".

El GMA se enmarca en un contexto en el que los derechos indígenas, si bien existen constitucionalmente y en tratados internacionales, difícilmente se respetan. Oaxaca se ha convertido en un espacio en el que se han entregado concesiones mineras sin previa consulta a comunidades indígenas, lo cual violenta sus derechos y fortalece el sistema extractivista, en donde los partidos políticos ingresan a comunidades a partir de prácticas como la cooptación y el clientelismo y desestabilizan sistemas políticos fundamentados en el trabajo voluntario y la organización colectiva.

En este sentido, la propuesta de los geoparques es en una alternativa de protección del territorio, del patrimonio geológico, en un espacio de formación técnica, pero también política encaminada al cuidado y protección de espacios catalogados como ancestrales por su tradición cultural e histórica. Abre un nuevo

4 Cita tomada de audio del taller sobre "Defensa del Territorio" realizado el día 22 de octubre del 2017. Participación de Daniela Juárez, representante de la autoridad legítima de San Juan Yucuita. 
camino de construcción de autonomía indígena no necesariamente de carácter confrontativo, sino fundamentado en la negociación, el diálogo y el respeto al estado de derecho con fundamento en políticas de protección ambiental, de respeto a los derechos indígenas y de cuidado del patrimonio geológico. También se convierte en un espacio de oportunidad para la generación de otras formas de potenciar procesos económicos centrados en conocimientos locales, saberes milenarios y formas de organización comunitaria.

\section{METODOLOGÍA}

En América Latina ha existido un desarrollo importante de metodologías de corte cualitativo que parten de experiencias concretas vinculadas a la transformación social y al compromiso con grupos sociales excluidos y violentados simbólica y físicamente. El desarrollo de estas metodologías puede rastrearse hacia la segunda mitad del siglo XX, a partir de dos acontecimientos. La creación de la Pedagogía de la liberación de Paulo Freire $(2002 ; 1969)$ y la Declaración de Barbados $^{5}$, espacio de reflexión en donde antropólogos y científicos sociales se comprometieron a erradicar el saqueo de información y a colaborar con los pueblos originarios que pujaban por su emancipación neocolonial.

Estas metodologías se enmarcan en procesos en los que los individuos y sus decisiones son el centro de la reflexión. El objetivo es promover mecanismos participativos que deriven en acciones concretas (Dueñas et al, 2012). Algunos elementos que dan forma a estas investigaciones son el diagnóstico, la sistematización, la descripción, la valoración del saber local y el diseño de propuestas de transformación de la realidad (Cox, 1996). Algunos de los resultados esperados son la transición de los individuos, de objetos de políticas en sujetos de política, de derechos y partícipes de sus procesos de desarrollo, lo cual lleva a la participación y al fortalecimiento de la democracia (Contreras, 2002).

Dos paradigmas metodológicos que se circunscriben al contexto descrito son la Educación Popular (EP) y la Investigación Acción Participativa (IAP) (Colmenares, 2012). En este trabajo me centraré particularmente en la educación popular y sus manifestaciones teórico-prácticas. Esta propuesta educativa puede considerarse, como se mencionó anteriormente, un legado de la pedagogía de la liberación de Paulo Freire, que después ha adquirido diversos matices y se ha integrado a múltiples objetivos liberadores y/o de generación de conciencia crítica, desbordando sus pretensiones iniciales de alfabetización crítica de adultos. Desde los años 60 y 70's ha sido una metodología para la formación de líderes comunitarios que reivindican diversas luchas, defensa del territorio, cuidado del agua, defensa del maíz, protección de derechos (Freedman et al, 2014).

${ }^{5}$ Para profundizar sobre la Declaración de Barbados consultar el siguiente link: http://www. libertadciudadana.org/archivos/Biblioteca\%20Virtual/Documentos\%20Informes\%20Indigenas/ Documentos\%20Internacionales/Declaracion\%20de\%2010s\%20Pueblos\%20Indigenas/Declaracion\%20Barbados\%201971.pdf 
Estos procesos se han desarrollado fundamentalmente desde Organizaciones No Gubernamentales (ONGs), aunque en las últimas décadas también han sido retomados por un sector crítico perteneciente a la academia y con procesos de investigación de incidencia social (Gómez, 2016; Serrano, 2017).

Un elemento central en las metodologías emanadas de la EP es la concepción dialéctica del aprendizaje. Desde esta perspectiva del cómo generar conocimiento, se parte de la propia práctica de los sujetos, de su experiencia de lucha, de organización. Se identifican las contradicciones del proceder y se reflexiona sobre éstas. Una vez comprendidas las fallas del proceso, se procede a construir y proponer alternativas, en este paso la planeación estratégica se convierte en un elemento esencial e indispensable para la transformación (Van de Velde, 2008).

Las metodologías emanadas de la EP cuestionan directamente paradigmas de la investigación convencional como la objetividad o el análisis abstracto e individualizado de un fenómeno o problemática, afirmando que la investigación debe centrarse en el reconocimiento de los intereses de los involucrados, en la develación colectiva de las formas de dominación existentes y en el énfasis en la transformación de las realidades, no sólo en su descripción, lo que implica una posicionamiento ético-político con quienes se construye el conocimiento, y no sólo privilegiar el interés individual e intelectual del investigador (Mejía, 2014).

Dentro de este paradigma investigativo, el análisis de lo social y lo cultural tendría que desembocar en prácticas políticas, es decir, en la concreción de proyectos a partir de las concepciones de la realidad de los sujetos implicados, creando nuevas rutas de conocimiento y prácticas de diversa índole (Medina, 2006). También se ha establecido que la cultura enmarcada en modos específicos de vida se circunscribe a concepciones materiales y simbólicas específicas en un contexto de desigualdad y discriminación, que debe ser develado para generar estrategias de defensa de la vida, de la dignidad y la justicia (Rauber, 2016).

Algunos efectos de la formación política son la concreción de escuelas, e incluso sistemas educativos alternativos, en el diseño y aplicación de currículos fundamentados en los saberes y valores propios, en la experiencia de luchas por la democracia comunal y la creación de alianzas entre organizaciones sociales por la defensa de los recursos naturales a partir de estrategias en las que se combinan conocimientos catalogados como científicos y otros reconocidos como comunitarios y ancestrales (Baronnet, 2017).

Las diversas metodologías participativas, ya sea en su carácter escolarizado o fuera de las aulas y fortaleciendo procesos sociales, cuentan con herramientas de obtención de información y de generación de conciencia crítica, una de las más importantes es el taller desde la perspectiva de la EP. Este tipo de talleres se caracterizan por su dimensión política que implica un posicionamiento con respecto al o los grupos con los que se trabaja; su dimensión pedagógica se enfoca en trabajar en la lectura del mundo a partir del análisis de la realidad; y la dimensión ético-metodológica, que tiene que ver con la coherencia entre el decir y el hacer, entre los medios y los fines que se pretende alcanzar. Estas dimensiones se enmarcan en la generación de una estrategia dirigida al análisis, pero también a la concreción de actividades, por lo que se trata de procesos en los que se vin- 
cula la teoría con la práctica, el diálogo de saberes y la producción colectiva de aprendizajes (Cano, 2012).

Tomando en cuenta los elementos planteados de cómo se percibe la construcción del conocimiento desde la perspectiva de la EP - la concepción dialéctica del conocimiento, que implica el partir de una realidad concreta, de un proceso organizativo establecido, o de la intención de concretar uno a partir de la acción común y en defensa de algún recurso; o ideal, respetando el postulado de siempre partir del contexto socio-cultural y de respetar los intereses de los involucrados - se trabajó una serie de talleres con pobladores y pobladoras que asumieron el rol de guías del GMA. Se priorizó su participación por su trascendental papel en el cuidado y conocimiento de su territorio y en su compromiso de consolidar el GMA a partir de pensarlo como una alternativa de desarrollo local que toma en cuenta sus conocimientos, y se puede convertir en una plataforma para proyectar a la región en el mundo.

\section{TALLERES CON GUÍAS DEL GMA}

Durante los meses de agosto y diciembre del año 2017 inicié un trabajo de fortalecimiento a autoridades locales y guías del GMA a través de la aplicación de talleres sobre "defensa del territorio" que fueron generando otros temas de interés para los participantes como "estructura organizativa" y "sensibilización sobre el geoparque". Dentro de los resultados de los talleres existe un punto que destaco, y que iré explicitando poco a poco: la apropiación del territorio por parte de los guías a partir del establecimiento del geoparque.

Para argumentar sobre la apropiación del territorio haré referencia a dos talleres que se realizaron con guías, uno de Sistematización de Experiencias, otro de Defensa del Territorio. A lo largo de los talleres se pudieron observar distintos niveles de apropiación del territorio por parte de los guías. En un primer nivel se destaca la parte organizativa, en un segundo nivel una apropiación educativa. Finalmente se muestra un caso concreto de apropiación desde la experiencia de Yucuita, municipio que integra el GMA.

En el plano organizativo el trabajo realizado por académicos de la UNAM, pobladores de los distintos municipios, autoridades comunales, municipales y agentes, así como los propios guías, ha abierto una ventana amplia de aspiraciones. El ideal más avanzado que se tiene, es que el proyecto logre unir a los nueve municipios y agencias involucradas a manera de un territorio común, más allá de fronteras geopolíticas o problemáticas históricas entre municipios. A partir de este paraguas aspiracional se engloban acepciones de lo que significa geoparque para los propios guías, como es el caso de la siguiente definición realizada por doña Tomasa, una de las guías con más experiencia y reconocimiento en el GMA: "Es una puerta de la esperanza que se abre de que se pueden llegar a grandes cambios para nuestros municipios",

${ }^{6}$ Extracto de taller "Sistematización de Experiencias" para guías realizado el día 8-10-17 en 
Si bien la definición podría entenderse como demasiado amplia, refleja esa esperanza de un proyecto que le haga justicia a un territorio históricamente olvidado por las autoridades en turno, un espacio considerado como ejemplo de desastre natural debido a la contundencia de los estragos de la erosión, pero que a partir de la reconstrucción histórica de la relación entre erosión e innovación cultural y tecnológica, realizada por los antiguos mixtecos, éstas adecuaciones del ser humano al contexto, y del contexto al ser humano, se han convertido en bandera de lucha de los actuales herederos de la cultura mixteca. La siguiente definición de lo que significa geoparque para el profesor Aniceto nos lleva de la esperanza del cambio fundado en el trabajo conjunto y la organización, a las acciones concretas: "Geoparque nos abre la posibilidad para adueñarnos de nuestro territorio, nos da poder de ser dueños de lo que es nuestro territorio"7.

La definición presentada no es menor debido a que la Mixteca es una región caracterizada por la migración de su población debido a la falta de oportunidades. El hecho de que el geoparque se convierta en un motivo para la lucha por el territorio, para conservarlo, es un cambio de mentalidad que, en la medida en que se consolide como una opción que genere mejores condiciones de vida para la población, sin duda que podrá ir consolidando el ideal del territorio geoparque más allá de fronteras municipales y de conflictos locales. Cabe destacar la vinculación realizada entre geoparque y cosmovisión, algo esencial y particular del GMA y su territorialización. Esto se puede apreciar en la siguiente acepción del término geoparque realizada por el Señor Valentín, una de las personas que más se han comprometido e introyectado el proyecto y el compromiso con su comunidad:

Hay caminos sagrados, hay cerros sagrados, hay fuentes de agua donde son sagrado, todo un territorio tiene un espacio sagrado, entonces para nosotros territorio geoparque tiene que ser sagrado... en la actualidad con la política que ostenta el sistema de gobierno, llega, tumba tu arroyo y lo convierte en drenaje, cual amor al río, o a lo que tienes, ¡eso ya no existe!, entonces nosotros tendríamos que trabajar esa parte, no perder esa visión ${ }^{8}$.

En el plano organizativo en donde destaca la convicción por unir y defender el territorio para lograr un cambio, una mejor vida y su vinculación con los más altos ideales de los mixtecos, como lo es la sacralidad de sus espacios, traeré a colación la siguiente reflexión de Yadira del municipio de Soyaltepec que refleja uno de los mayores resultados de unidad que ha generado el geoparque desde lo cotidiano, desde el vivir el día a día y el compartir las experiencias de trabajo,

el municipio de Yanhuitlán. Participación de la guía Tomasa Bautista del municipio de Tonaltepec.

7 Extracto de taller "Defensa del Territorio para guías" realizado el día 22-10-17 en el municipio de Yanhuitlán. Participación del guía y profesor de primaria Aniceto Bautista del municipio de Yanhuitlán.

${ }^{8}$ Extracto de taller "Defensa del Territorio para guías" realizado el día 22-10-17 en el municipio de Yanhuitlán. Participación del guía Valentín Velásquez, de la agencia de Santa María Suchixtlán. 
pero también los momentos de descanso y de participar en el consumo e intercambio de alimentos:

Eso nos va lograr hacer de unirnos, no, por decir, antes de geoparque, yo ¿cuándo conocía?, ¿cuándo compartía?, a lo mejor la comida como hoy con uno de Yanhuitlán, uno de Yucuita a lo mejor parece vacilada pero, poco a poco vamos a ir conociendo nuestras culturas y conociéndonos como seres humanos también y al mismo tiempo, también el día de mañana si algo llegara a afectarnos vamos a podernos defender todos, porque nos hace ser mejores seres humanos, podría ser mucho más amplio esto de territorio geoparque, nos enseñaría a aprender muchas cosas que sí están ahí, pero a lo mejor están muy guardadas 9 .

Con respecto al plano educativo, también se podría hacer una subdivisión, es decir, por un lado, un nivel del geoparque como espacio de generación de conciencia, de valoración del territorio, y por otro, una acepción del geoparque como espacio de fortalecimiento de las instituciones educativas existentes en la región y, finalmente, como un proyecto que forma técnicamente a muchos de los campesinos, artesanos, comerciantes o cualquier ciudadano interesado en participar en él.

Geoparque es realmente conocer nosotros, nuestra cultura, conocer nosotros lo que hay realmente en nuestro pueblo, en nuestro territorio, primero debemos de conocer y hacer conciencia con los demás para que podamos defender lo que realmente, lo que nos corresponde. Nosotros tenemos harta cultura que no conocemos, harto terreno que no sabemos ni dónde es ${ }^{10}$.

Esta acepción que ofreció don Esteban, uno de los guías más respetados por su edad y conocimiento, enfatiza el valor y amplitud de la cultura local y el potencial territorial con el que se cuenta, pero que no es conocido ni reflexionado de manera colectiva, lo que da pie para realizar una breve reflexión sobre los dos campos educativos en los que se trabaja desde los proyectos de investigación que se desarrollan por personal de la UNAM en el geoparque. Por un lado se encuentra la llamada "geoeducación" que se vincula con la generación de recorridos de los propios pobladores de las comunidades, preferentemente niños y jóvenes, para que conozcan y reconozcan su territorio, para que compartan y convivan con culturas vecinas, y en un momento dado enriquezcan el currículo de las escuelas de la región, la elaboración de material de difusión que permita el conocimiento de aspectos relacionados con el geoparque; la elaboración de charlas, conferencias, encuentros, que enriquezcan el conocimiento de los lugareños.

Por otro lado, se encuentra la formación política que involucra el fortalecimiento de autoridades, guías y población en general en temas como la defensa del territorio, la sistematización de experiencias, el ejercicio del poder o la es-

${ }^{9}$ Extracto de taller "Defensa del Territorio para guías" realizado el día 22-10-17 en el municipio de Yanhuitlán. Participación de la guía Yadira Jiménez del municipio de San Bartolo Soyaltepec.

10 Extracto de taller "Defensa del Territorio para guías" realizado el día 22-10-17 en el municipio de Yanhuitlán. Participación del guía Esteban Santiago de la agencia de Tiltepec. 
tructura organizativa. Con la geoeducación se pretende incidir en la valorización de la cultura, y de su vínculo con el territorio, con la formación política se trata de generar y/o fortalecer la conciencia crítica en el sentido freireano, y de la educación popular, es decir, generar herramientas que permitan la transformación de la realidad a partir de conocimientos propios.

En la información obtenida en los talleres, destaca la manera en la que los guías se han apropiado de los conocimientos técnicos que han proporcionado distintos investigadores del instituto de geografía de la UNAM, mostrando una manera novedosa de vinculación entre universidad y comunidad. La profesionalización de los guías bajo la tutela de investigadores muestra una arista poco explorada en la formación de recursos humanos, en la que la relación no necesariamente se encuentra mediada por la burocratización que implica la acreditación de ciertos grados para acceder a la educación y la formación profesional.

Muchos de los guías truncaron su formación escolar en la primaria, por lo que la formación que les brinda la UNAM a través del instituto de geografía se convierte en un gran aliciente, una motivación importante para ellos y ellas, es decir, lo que no pudieron lograr por falta de recursos, por la exclusión en la que se encuentran y/o por falta de estructura educativa, ahora lo están cristalizando en el marco del proyecto geoparque. El siguiente testimonio de Felipe, uno de los llamados guías de naturaleza más experimentados, es contundente en este sentido:

... yo en mi caso aprendí unas cosas, y me dediqué a estudiar lo que es una piedra, lo que es un suelo, lo que es la geología para al rato saber explicarle a mis visitantes de qué se trata el tema, porque uno puede estar en un área, si no nos interesa esta área, tampoco lo puede uno meter uno a la fuerza, aunque lo nombre el pueblo, porque en este caso, bueno, si yo me dedico a cuidar borregos, pues ese es mi tema, pero en este caso si uno se mete a esto de estudiar lo que es la geología para que al rato vengan nuestros visitantes y uno interprete o trate uno de interpretarles a los que vienen, y así me ha tocado varios temas, no solamente geología, como les comentaba soy de naturale$\mathrm{za}, \mathrm{y}$ me interesó muchos otros temas que yo desconocía, que en mi caso yo no estudié, yo ni siquiera fui a la secundaria y ahí estoy arriba de más de uno que va a la secundaria porque he estudiado infinidad de temas, sé observación de aves, sé monitoreo de vertebrados, sé algo de plantas, sé interpretación de paisaje, y otros temas, más la geología, todo depende de uno ${ }^{11}$.

La cita anterior muestra la manera en la que el trabajo conjunto entre pobladores, ahora guías, e investigadores de la universidad, da sus frutos; y los pobladores pueden formarse y desarrollarse en temáticas y roles, que difícilmente podrían haberlo hecho sin el trabajo colegiado, y que impacta de manera contundente en la autoestima de quienes logran percibir la ampliación de sus conocimientos, pero también en los investigadores que, poco a poco incursionan en metodologías participativas que sensibilizan el quehacer académico y en

11 Extracto de taller "Sistematización de Experiencias para guías realizado el día 8-10-17 en el municipio de Yanhuitlán. Participación del guía Felipe Pérez del municipio del Tiltepec. 
algún momento pueden despertar o fortalecer su posicionamiento ético-político, haciendo real el aforismo freireano: "todos nos educamos a todos".

Para concluir traeré a colación el caso del municipio de Yucuita debido a que brinda elementos de análisis para entender fundamentos de la defensa del territorio y la renuencia de muchos pueblos a permitir que se exploten sus espacios, situación poco comprendida por las instancias gubernamentales, que muchas veces se empeñan en seguir estableciendo proyectos de "desarrollo" y/o políticas públicas de arriba hacia abajo, de manera vertical y sin consultar a los "beneficiados" del "progreso", aun teniendo el derecho a la consulta, consagrado en tratados internacionales como el convenio 169 de la Organización Internacional del Trabajo (OIT).

El problema en el municipio de Yucuita inició en agosto del 2017 cuando se esparció el rumor de que el presidente municipal había acordado con empresarios y con autoridades estatales la instalación de una empresa en la localidad. Este hecho se realizó sin convocar a asamblea comunitaria para informar sobre el establecimiento de la fábrica, hecho contrario a la forma de organización interna de muchas comunidades indígenas en las que aún se organizan a partir de los llamados "usos y costumbres".

La consecuencia del ocultamiento de información fue la destitución del presidente municipal por parte de la comunidad y la instalación de nuevas autoridades en asamblea comunitaria. Desde su nombramiento, las autodenominadas "autoridades legítimas" se acercaron al geoparque, primero a recibir información de qué se trataba el proyecto, debido a que la comunidad no había sido informada por parte del presidente municipal destituido. Así, las autoridades legítimas comenzaron a acercarse al geoparque y participar activamente nombrando guías y estableciendo un recorrido para los visitantes. A continuación, presento el testimonio de la profesora Rufina, una de las representantes del municipio:

En la población de Yucuita iban a poner una fábrica. En primer lugar, no le habían dado información a la comunidad de lo que estaban haciendo las autoridades, todo lo estaban haciendo pues clandestinamente, los permisos y todo iban a poner una fábrica de origen coreano de focos led. Poner una fábrica de ese tipo pues, trae consecuencias, es cierto que a lo mejor van a dar empleo no se a cuantas personas, pero atrás de eso hay muchas desventajas, muchas implicaciones para la población ${ }^{12}$.

Es importante observar la manera en la que se pone en tensión y se cuestiona la idea de "desarrollo" que tradicionalmente se aplica a comunidades marginadas, y que tiene que ver con una visión anclada en la explotación de los recursos naturales a favor de las grandes industrias, pero que pocas veces se entienden o exploran otras acepciones del término "desarrollo" que se tejen desde comunidades, y que podrían potenciar otras formas de entender el territorio, más allá de un espacio industrializable. Se podría resignificar el término desarrollo

${ }^{12}$ Extracto de taller "Defensa del Territorio para guías" realizado el día 22-10-17 en el municipio de Yanhuitlán. Participación de la representante del municipio de Yucuita Rufina Hernández 
a partir de conocimientos locales, y potenciarlos con tecnologías de punta para ofrecer formas alternativas de vida, que no violenten las legítimas continuidades históricas de los territorios y las formas culturales que han sobrevivido a lo largo del tiempo. Este planteamiento puede ser reforzado con la participación de Daniela Juárez representantes del municipio:

A mí se me queda muy grabada una palabra, que dicen que desarrollo. Las personas que, con este tipo de empresas, o de fábricas, con la imagen que se van es con desarrollo, desarrollo para una comunidad, ¿por qué piensan que desarrollo es una fábrica?, ¿por qué no mejor pensar que un desarrollo es explotar de una manera sustentable lo que hacemos?, nuestro trabajo, ¿por qué no desarrollo es pensar que podemos compartir lo que vivimos, compartir nuestras casas con la gente? Es lo que siempre te venden, que desarrollo es igual a fábricas, a trabajos, pero ¿por qué no pensar que desarrollo es el aire puro que vivimos?, que respiramos actualmente y es lo que debemos tener muy en cuenta siempre, que nuestro desarrollo es vivir en paz $^{13}$.

Una participación que engloba el tema que se discute, es decir, la relación entre "apropiación-despojo" de los territorios en donde se asientan muchos pueblos originarios, y que se conecta con la visión de "desarrollo" a partir de la implementación de complejos industriales y con la falta de consulta a los pueblos se puede apreciar en las palabras del señor Esteban de Tiltepec:

En mi comunidad se está tratando el sistema del aprovechamiento de recursos naturales como la resina, sin en cambio la misma comunidad, por la ignorancia de no saber a lo que se están metiendo, corre el riesgo de que alguien del norte, una empresa ya constituida y que puede abarcar, puede mandar trabajadores al pueblo de Tiltepec a que recolecten la resina. En mi pueblo, muchos de los que se comprometieron a ese trabajo no lo ejecutan como debe de ser, están produciendo menos de lo que deberían de producir, y si una empresa ve que esa potencia, manda a otros trabajadores y a la mejor los trabajadores de mi pueblo van a decir, ite voy a pagar tanto por acarreármela, más no por recolectarla! Es ahí donde se aprovechan de la ignorancia del pueblo en cualquier índole, sea en la resina, sea en el agua, sea en la pesca, cualquier germinado, producto que se tenga natural, las empresas se aprovechan de la ignorancia de los pueblos ${ }^{14}$.

Es precisamente este el corazón de la argumentación: la relación de desigualdad, la explotación de los recursos locales para el beneficio de otros, muchas veces muy lejanos, la histórica vulneración de derechos de los pueblos, el saqueo, el empobrecimiento humano y de recursos de los territorios. Cuando se establecen industrias en territorios habitados por pueblos originarios, muchas veces lo que importa ahí es la materia prima, lo humano pasa a segundo término, los

${ }^{13}$ Extracto de taller "Defensa del Territorio para guías" realizado el día 22-10-17 en el municipio de Yanhuitlán. Participación de la representante del municipio de Yucuita Daniela Juárez

${ }^{14}$ Extracto de taller "Defensa del Territorio para guías" realizado el día 22-10-17 en el municipio de Yanhuitlán. Participación del guía Esteban Santiago de la Agencia de Tiltepec. 
"mejores trabajos", o por lo menos, los mejor remunerados, no suelen ser para los locales, la mano de obra calificada normalmente proviene de otros lugares.

Esto provoca un deterioro del tejido social donde los habitantes son desplazados y/o relegados a los espacios de menor importancia en la industria, o a realizar actividades periféricas que no necesariamente cuentan con la cobertura legal, y/o de protección laboral elemental. Dejan de ser dueños de su territorio y su situación de marginación, explotación y exclusión adquiere matices perennes. Tal situación es entendida perfectamente por muchos de los habitantes de los pueblos originarios; es por este motivo que el proyecto geoparque ha sido acogido de manera esperanzadora por los nueve municipios que lo integran.

No es casual que en el caso de Yucuita las autoridades legítimas hayan tomado como bandera de lucha al geoparque, y lo confronten con la visión desarrollista de la fábrica en cuestión. La tarea es lograr que los lazos construidos entre academia y comunidad puedan fraguar y con esto impulsar una visión de desarrollo que sea alternativa, novedosa, con tintes de lucha y resistencia indígena pacífica. El geoparque es un importante laboratorio que permite educar en distintos niveles, desde turistas, estudiantes-académicos y a las mismas autoridades gubernamentales, esto de hecho ya se está observando. De manera lenta, pero alentadora se ha observado un cambio de visión en muchos funcionarios públicos que se han acercado al geoparque, aunque ellos mismo lo admiten, y nosotros como académicos en nuestra relación con distintas autoridades lo hemos observado, las legislaciones actuales y la visión cerrada de muchos funcionarios de alto nivel, ponen en jaque alternativas de desarrollo como la del geoparque.

\section{REFLEXIONES FINALES}

A más de dos décadas del levantamiento del Ejercito Zapatista de Liberación Nacional (EZLN), los pueblos originarios de México siguen sin ser tomados en cuenta de manera contundente en las políticas públicas del Estado, al contrario, siguen siendo objeto de políticas asistencialistas, y de acoso por parte de partidos políticos, si bien sus derechos se han inscrito constitucionalmente en algunos estados, y constantemente se apela a los tratados internacionales para referir a su libre determinación, ésta se encuentra muy lejos de concretarse.

Proyectos como el de los geoparques mundiales se convierten en una nueva esperanza para lograr consolidar lo que en Chiapas el EZLN o la Organización Sociedad Civil Las Abejas de Acteal han realizado, o lo que otros movimientos como en Cherán o Nurio en Michoacán se lograron, es decir, la libre determinación de los pueblos, la construcción de otros mundos posibles que puedan convertirse en alternativas reales, globales, ante la visión hegemónica de la geopolítica mundial, logrando evitar la ruptura entre productor y producto, entre conocimiento y cultura, lo que, desde la perspectiva neo marxista se ha denominado como la alienación de las subjetividades, la conversión del campesino, del artesano, del comerciante en mano de obra sustituible, explotable, "mal pagada", al servicio de la acumulación del capital en pocas manos. 
Planteo que los geoparques pueden convertirse en una nueva esperanza debido a que éstos no son una receta, su configuración depende directamente de las necesidades, intereses, ideales y proyectos de las propias comunidades que le dan sentido, así como de las características territoriales que lo conforman. Es una apuesta sólida y frágil a la vez. Si las comunidades cuentan con el respaldo de instituciones educativas que fortalezcan los proyectos comunitarios y con el de las instituciones de gobierno correspondientes, pueden convertirse en un nuevo modelo de desarrollo para los pueblos, en caso contrario los geoparques corren el riesgo de reproducir las desigualdades existentes y convertir a las comunidades en vitrinas del folklor, de saqueo, despojo territorial y cultural.

Particularmente en este artículo se utilizó al taller como herramienta para visualizar todo un entramado metodológico y concepción de investigación que es importante impulsar y concretar. La información y la sistematización de los conocimientos generados en los talleres permiten situar en tiempo y espacio específico concepciones como la lucha contra el despojo territorial, la territorialización, la apropiación del territorio a partir de su reconocimiento y valorización, pero también visibilizan todo un proceso de educación y formación política a partir de la construcción de identidad colectiva y de ejercicio del poder.

Este modelo educativo permite entender la concepción dialéctica del aprendizaje en el sentido de observar una realidad, analizarla, rescatar elementos culturales y ponderar la importancia de la organización que se convierte en práctica a partir de la acción, que se concreta en la defensa del territorio - en Yucuita por ejemplo -, o en la mejora de los procesos de colecta de resina, en Tiltepec. El imaginar la construcción del geoparque a partir de referentes culturales, políticos y organizativos locales es el primer paso para lograr una planeación estratégica robusta que se podrá concretar en la medida que los procesos organizativos se fortalezcan, en este sentido la Educación Popular tiene muchos elementos que aportar. El camino está trazado, resta observar y analizar en algunos años el proceso que en el 2014 inició con mucha esperanza en la Mixteca Alta y que entre el año 2017 y el 2019 ha ilusionado como una alternativa frente a prácticas de despojo cultural, territorial y político.

\section{BILIOGRAFÍA}

Abarca, A. F. (2016) "La metodología participativa para la intervención social: Reflexiones desde la práctica" Revista Ensayos Pedagógicos, vol. XI, núm. 1, págs. 87-109 Consultado el día 6 de agosto del 2018, disponible en: http://www.revistas.una.ac.cr/ index.php/ensayospedagogicos/article/view/8470/9719

Aedo, G. A. J. (2008) "Percepción del espacio y apropiación del territorio entre los Aymara de Isluga" Revista Estudios Atacameños, núm. 36, págs. 117-137, consultado el día 8 de agosto del 2018, disponible en: https://scielo.conicyt.cl/pdf/eatacam/n36/ art07.pdf 
Azamar, A. y Ponce, J. I. (2014) "Extractivismo y desarrollo: los recursos minerales en México, Revista Problemas del Desarrollo, vol. 45, núm. 179, págs. 137-158, consultado el día 23 de octubre del 2017, disponible en: http://www.redalyc.org/articulo.oa? id=11832064007

Bahía de Aguiar, P. C., Souza dos Santos, M. A. M. y De Oliveira, F. E. (2013) “Áreas naturales protegidas: una breve historia del surgimiento de los parques nacionales y reservas extractivas", Revista Geográfica de América Central, núm. 50 págs. 195213, consultado el día 24 de octubre del 2013, disponible en: http://www.revistas. una.ac.cr/index.php/geografica/article/view/5396/5228

Barabas, A. M. (2004) "La territorialidad simbólica y los derechos territoriales indígenas: reflexiones para el Estado pluriétnico", Revista Alteridades, vol. 14, núm. 27, págs. 105-119, México, consultado el día 4 de agosto del 2018, disponible en: http:// www.redalyc.org/pdf/747/74702706.pdf

Baronnet, B. (2017) "Estrategias alternativas de educación en las luchas de los pueblos originarios en México”, Educ. Soc. vol. 38, núm. 140, págs. 689-704, consultado el día 8 de noviembre del 2017, disponible en: http://www.scielo.br/pdf/es/ v38n140/1678-4626-es-38-140-00689.pdf

Bruno-Jofré, R. (2016) "Educación popular en América Latina durante la década de los setenta y ochenta: una cartografía de sus significados políticos y pedagógicos”, Foro de educación, vol. 14, núm. 20, págs. 429-451, consultado el día 11 de agosto del 2018, disponible en: http://forodeeducacion.com/ojs/index.php/fde/article/view/442/317

Cano, A. (2012) "La metodología de taller en los procesos de educación popular", Revista Latinoamericana de Metodología de las Ciencias Sociales, vol. 2, núm. 2, págs. 22-51, consultado el día 24 de octubre del 2017, disponible en: http://www.memoria. fahce.unlp.edu.ar/art_revistas/pr.5653/pr.5653.pdf

Carcavilla, U. L. y García, C. A. (s/f) "Geoparques, significado y funcionamiento", Ministerio de Economía y Competitividad de España e Instituto Geológico y Minero de España. Consultado el día 10 de septiembre del 2018, disponible en: http://www. igme.es/patrimonio/geoparques-igme2014-1.pdf

Carut, M.A., Torre, F., Moscoso, P. y Carut, C. (2017) "Geoparque Pillán Mahuiza, San Martín de los Andes, XX Congreso Geológico Argentino, del 7 al 11 de agosto, Tucumán, Argentina, consultado el día 24 de octubre del 2017, disponible en: http:// www.memoria.fahce.unlp.edu.ar/trab_eventos/ev.9418/ev.9418.pdf

Carreño, M. (2010) "Teoría y práctica de una educación liberadora. El pensamiento pedagógico de Paulo Freire", Cuestiones Pedagógicas, núm. 20, págs. 195-214, consultado el día 9 de septiembre del 2018, disponible en: https://institucional.us.es/revistas/cuestiones/20/art_10.pdf

Ceceña, A.E. (2017) "Los territorios de la guerra, las guerras del territorio", Revista América Latina en movimiento, núm. 527, págs. 1-5, consultado el día 24 de octubre del 2017, disponible en: https://www.alainet.org/sites/default/files/alem527.pdf

Colmenares, E. A. M. (2012) Investigación-acción participativa: una metodología integradora del conocimiento y la acción, consultado el día 12 de diciembre de 2019, Voces y Silencios. Revista Latinoamericana de Educación, 3(1), 102-115, disponible en: https://revistas.uniandes.edu.co/doi/pdf/10.18175/vys3.1.2012.07 
Composto, C. y Navarro, M. L. (2014) “Claves de lectura para comprender el despojo y las luchas por los bienes comunes naturales en América Latina" págs. 33-75 en Composto C. y Navarro M. L (Compiladoras) Territorios en disputa. Despojo capitalista, luchas en defensa de los bienes comunes naturales y alternativas emancipatorias para América Latina, Bajo tierra ediciones, México, D.F, consultado el día 13 de julio del 2018, disponible en: http://otrosmundoschiapas.org/docs/territorios_en_ disputa_bienes_comunes.pdf

Contreras, R. (2002) "La Investigación Acción Participativa (IAP):revisando sus metodologías y sus potencialidades" en Durston John y Miranda Francisca (compiladores) Experiencias y metodología de la investigación participativa, pp. 9-18, Naciones Unidas-CEPAL, Santiago de Chile, consultado el día 24 de octubre del 2017, disponible en: http://repositorio.cepal.org/bitstream/handle/11362/6024/S023191_es. pdf? sequence $=1 \&$ is Allowed $=\mathrm{y}$

Cox, A. R. (1996) "El saber local: metodologías y técnicas participativas", Centro de Información para el Desarrollo CID, La Paz Bolivia, consultado el día 24 de octubre del 2017, disponible en: http://www.cedet.edu.ar/Archivos/Bibliotecas_Archivos/ El\%20saber\%20local.pdf

Delgado, R. G. C. (Coordinador) (2013 a) "Ecología Política del extractivismo en América Latina: casos de resistencia y justicia socioambiental, CLACSO, Buenos Aires, Argentina, consultado el día 23 de octubre del 2017, disponible en: http://biblioteca. clacso.edu.ar/clacso/posgrados/20131218030905/EcologiaPolitica.pdf

(2013 b) “PPorqué es importante la ecología política?” Revista Nueva Sociedad, núm. 244, consultado el día 25 de octubre del 2017, disponible en: http://www. ungs.edu.ar/colca2014/wp-content/uploads/2013/10/Gian-Carlo-Porque-es-importante-la-ecologia-politica.pdf

Dueñas, S. L. R., León, G. B., García, L. E. J. (2012) “Los procesos participativos como metodologías para el desarrollo local. El caso de los chileros de pardo, San Luis Potosí, México", Razón y Palabra, núm. 80, consultado el día 24 de octubre del 2017, disponible en: http://www.razonypalabra.org.mx/N/N80/M80/17_DuenasLeonGarcia_M80.pdf

Espinosa, R. L. M. (2016) "Geoparque en el distrito minero Tlalpujahua-El Oro, Ciencia UAT, núm. 11, consultado el día 26 de octubre del 2017, disponible en: http://www. redalyc.org/html/4419/441949672002/

Fernández Da Silva, L. M. C, MorbecRk De Oliveira, A. K y Ramos, B. V. L. (2016) "Public policies development: convergences and divergences in the bodoquena pantanal geopark, Ambiente y sociedad, vol XIX, núm. 3, págs. 157-176, consultado el día 25 de octubre del 2017, disponible en: http://www.memoria.fahce.unlp.edu.ar/ trab_eventos/ev.9418/ev.9418.pdf http://www.scielo.br/pdf/asoc/v19n3/1809-4422asoc-19-03-00155.pdf

Freedman, E., Barrera, T. E., Payés, I. (2014) "Mapeo de experiencias de educación popular con movimientos sociales" Consejo de Educación Popular de América Latina y el Caribe CEAAL, Lima Perú, consultado el día 8 de noviembre del 2017, disponible en: http://biblioteca.clacso.edu.ar/Costa_Rica/ceaal/20160506015605/documentotrabajo_3.pdf

Freire, P. (2002) Pedagogía del oprimido, Siglo XXI editores, España. (1969) Educación como práctica de la libertad, Ed. Siglo XXI editores, Uruguay. 
Gómez, J. A. C. (2016) La pedagogía social en el diálogo de las universidades con la educación popular y la educación social, consultado el día 10 de diciembre del 2019, Revista Interamericana de Educación de Adultos, 38(1), 85-106, disponible en: https://www.redalyc.org/pdf/4575/457545337006.pdf

González, M. (2010) "Autonomías territoriales indígenas y regímenes autonómicos (desde el Estado en América Latina”, en González, Miguel, Burguete, C. M. Aracely y Ortiz-T Pablo (Coords) La autonomía a debate. Autogobierno indígena y Estado plurinacional en América Latina, pp. 35-62, FLACSO Ecuador, Ecuador. Consultado el día 3 de agosto del 2018, disponible en: https://www.servindi.org/pdf/ Autonomia_a_debate.pdf

Guevara, C. R. D. (2009) La resistencia indígena: una forma de fortalecer la cultura, la autoridad y los derechos humanos", Revista Historia Actual Online, núm. 20, págs. 61-66, consultado el día 8 de agosto del 2018, disponible en: https://historia-actual. org/Publicaciones/index.php/haol/article/viewFile/315/302\&a=bi\&pagenumber=1 $\& \mathrm{w}=100$

Harvey, D. (2005). "El “nuevo" imperialismo: acumulación por desposesión”, CLACSO, págs. 98-129, consultado el día 23 de octubre del 2017, disponible en: http://biblioteca.clacso.edu.ar/clacso/se/20130702120830/harvey.pdf

Hernández, F. M. y Furlan, A. (2016) "El discurso como ejercicio de la territorialidad. Disputas y discursos territoriales en la costa marítima de Buenos Aires (Argentina)", Cuadernos Geográficos, vol. 55, núm. 1, págs. 59-91, Granada España, consultado el día 4 de agosto del 2018, disponible en: http://www.redalyc.org/ pdf/171/17146265003.pdf

Infante, A. (2013) "El porqué de una epistemología del sur como alternativa ente el conocimiento europeo" en Fermentum. Revista Venezolana de Sociología y Antropología, vol. 23, núm. 68 págs. 401-411, Universidad de los Andes Mérida, Venezuela. Consultado el día 18 de septiembre, disponible en: http://www.redalyc.org/ pdf/705/70538671007.pdf

Ishizawa, O. J. y Rengifo, V. G. (2012) "Diálogo de saberes. Una aproximación epistemológica" AMC EDITORES, Lima, Perú, consultado el día 18 de septiembre del 2018, disponible en: http://www.pratecnet.org/pdfs/Dialogo-saberes-aproxim-epist. pdf

Lara, L. S. (2016) "Estrategias de apropiación territorial en un contexto de relación interétnica en Guamal, Caldas", Revista Colombiana de Antropología, vol. 52, núm. 1, págs. 117-138, Colombia, consultado el día 8 de agosto del 2018, disponible en: http://www.scielo.org.co/pdf/rcan/v52n1/v52n1a06.pdf

Leff, E. (2003) "La ecología política en América Latina: un campo en construcción", Sociedade e Estado, vol. 18, núm. 1/2, págs. 17-40, consultado el día 24 de octubre del 2017, disponible en: http://www.scielo.br/pdf/se/v18n1-2/v18n1a02.pdf

Maestrocola, Y., Salgado, L. y Casadío, S. (2014) "Geoparque y turismo en Cerro Azul: estrategia para la conservación del patrimonio geológico", VI Congreso Latinoamericano de investigación Turística, del 25 al 27 de septiembre, Neuquen, consultado el día 25 de octubre del 2017, disponible en: http://170.210.83.98:8080/jspui/bitstream/123456789/435/1/27\%20Mastrocola\%20\%26\%20Salgado\%20et\%20al.pdf 
Márquez, R. C. y Legorreta, D. M. C (2017) “Apropiación territorial, cultura y poder: Propuesta conceptual para el estudio de comunidades indígenas y campesinas en el contexto mexicano", Revista Orbis Latina, vol. 7, núm. 3, págs. 46-61, Brasil, consultado el día 5 de agosto del 2018, disponible en: https://www.researchgate.net/ publication/322817587_APROPIACION_TERRITORIAL_CULTURA_Y_PODER_PROPUESTA_CONCEPTUAL_PARA_EL_ESTUDIO_DE_COMUNNIDADES_INDIGENAS_Y_CAMPESINAS_EN_EL_CONTEXTO_MEXICANO

Martínez, G. P. (2008) "Conquista, olvido, despojo, eje del exterminio de los pueblos indígenas en el Noroeste y Norte de México", Observatoire des Amériques, Núm. 18., Universidad de Quebec, Canada. Consultado el día 13 de julio del 2018. Disponible en: http://www.ieim.uqam.ca/IMG/pdf/Chro-MARTINEZ-18-08.pdf

Martínez, C. R. y Haro, E. J. A. (2015) "Derechos Territoriales y pueblos indígenas en México: una lucha por la soberanía y la nación” Revista Pueblos y Fronteras, vol. 10, núm. 19, págs. 228-256, México, consultado el día 6 de agosto del 2018, disponible en:

http://www.redalyc.org/pdf/906/90638786010.pdf

Mbembe, A. (2011) "Necropolítica seguido de sobre el gobierno privado indirecto", Editorial Melusina, España, consultado el día 23 de octubre del 2017, disponible en: https://aphuuruguay.files.wordpress.com/2014/08/achille-mbembe-necropolc3adticaseguido-de-sobre-el-gobierno-privado-indirecto.pdf

Medina, M. P. (2006) "Juan Carlos Mijangos Noh. Educación popular y desarrollo comunitario sustentable, una experiencia con los mayas de Yucatán. México", Revista Interamericana de Educación de Adultos, vol. 28, núm. 2, págs. 211-215, consultado el día 8 de noviembre del 2017, disponible en: http://www.redalyc.org/ pdf/4575/457545086015.pdf

Mejía, N. J. (2015) "La investigación social en América Latina. Posibilidades metododógicas", RELMECS, vol. 5, núm. 1, págs. 1-4, consultado el día 12 de agosto del 2018, disponible en: http://www.memoria.fahce.unlp.edu.ar/art_revistas/pr.6664/ pr.6664.pdf

Mejía, M. R. (2014) "La educación popular: Una construcción colectiva desde el sur y desde abajo" en Revista Archivos Analíticos de Políticas Educativas, 22 (62) Consultado el día 13 de mayo del 2020, disponible en: https://www.redalyc.org/ pdf/2750/275031898079.pdf

Modonesi, M. e Iglesias, M. (2016) "Perspectivas teóricas para el estudio de los movimientos sociopolíticos en América Latina: ¿cambio de época o década perdida? Revista De Raíz Diversa, vol. 3, núm. 5, págs. 95-124, consultado el día 3 de agosto del 2018, disponible en: http://latinoamericanos.posgrado.unam.mx/publicaciones/ deraizdiversa/no.5/4._Perspectivas_teoricas_para_el_estudio_de_los_movimientos_sociopoliticos_en_America_Latina-_cambio_de_epoca_o_decada_perdida._Massimo_Modonesi,_Monica_Iglesias.pdf

Muñoz, C. M. J. (2013) "El conflicto en torno al territorio indígena Parque Nacional Isiboro Sécure: Un conflicto multidimensional”, Revista Cultura y Representaciones Sociales, núm. 14, págs. 100-141, consultado el día 8 de agosto del 2018, disponible en:

http://www.scielo.org.mx/pdf/crs/v7n14/v7n14a4.pdf

Organización de las Naciones Unidas ONU (2018) "Informe de la Relatoría Especial sobre los derechos de los pueblos indígenas sobre su visita a México", Consejo de Derechos Humanos, consultado el día 11 de agosto del 2018, disponible en: https:// www.hchr.org.mx/images/doc_pub/2018-mexico-a-hrc-39-17-add2-sp.pdf 
Orozco, L. E. (2015) "Lucha, resistencia y formación política en la región Altos de Chiapas", en Bautista Eduardo, Garza Manuel y Matamoros Fernando (coords.) Participación y rupturas de la política en México. Subjetividad, luchas y horizontes de esperanza, pp. 191- 210, Editorial Porrúa, Universidad Autónoma Benito Juárez de Oaxaca UABJO, México.

Ortiz, P. L. (2004) "El silencio como forma de resistencia civil. Análisis del discurso del EZLN, 1997-2001”, Revista Venezolana de Economía y Ciencias Sociales, vol. 10, Núm. 1, págs. 109-127, consultado el día 9 de agosto del 2018, disponible en: http://www.redalyc.org/html/177/17710107/

Osorio, R. M. L y Contreras, H. A. (2009) "El diagnóstico rural participativo y el manejo de los recursos naturales" Estudios Agrarios, Procuraduría agraria, págs. 109-136, consultado el 10 de septiembre del 2018, disponible en: http://www.pa.gob.mx/publica/rev_42/ANALISIS/Mar\%C3\%ADa\%20Luisa\%20Osorio_8.pdf

Palacio, J. L. (2013) "Geositios, geomorfositos y geoparques: importancia, situación actual y perspectivas en México", Boletín del Instituto de Geografía UNAM, núm. 82, págs. 24-37, consultado el día 25 de octubre del 2017, disponible en: http:// www.redalyc.org/articulo.oa?id=56928965003

Portillo, R. L. H. (2014) "Extractivismo clásico o neoextractivismo: ¿dos tipos de extractivismos diferentes?, Revista Tendencias, vol. XV, núm. 2, julio-diciembre, págs. 11-29, consultado el día 23 de octubre del 2017, disponible en: http://revistas.udenar.edu.co/index.php/rtend/article/view/2053/2440

Quecedo, R. y Castaño, C. (2002) "Introducción a la metodología de la investigación cualitativa" Revista de psicodidáctica, núm. 14, págs. 5-39, consultado el día 12 de agosto del 2018, disponible en: http://www.redalyc.org/pdf/175/17501402.pdf

Ramírez, E. A., González, E. y Espinosa M. N (2014) "La apropiación política del territorio. Estrategias de participación política y de resistencia campesina en los llanos del Yarí”, Revista AGO.USB, vol. 14, núm. 1, págs. 177-202, Medellín, Colombia, consultado el día 10 de agosto del 2018, disponible en: http://www.scielo.org.co/pdf/ agor/v14n1/v14n1a09.pdf

Rauber, I. (2016) "Educación popular, Interculturalidad y descolonización: la construcción del sujeto de las transformaciones sociales en los movimientos de mujeres", Graduate Institute Publications, págs. 212-232, consultado el día 8 de noviembre del 2017, disponible en: http://books.openedition.org/iheid/6322

Roa, A. T. (2014) "Época de resistencias al extractivismo" en Roa A. Tatiana y Navas L. María (Coords.) Extractivismo, conflictos y resistencias pp. 39-66, AMIGOS DEL A TIERRA - COLOMBIA y Escuela de la sustentabilidad, Bogotá, Colombia, consultado el día 3 de agosto del 2018, disponible en: https://www.cpalsocial.org/documentos/535.pdf

Rosado, G. E. M. y Ramírez, M. X. (2017) "Importancia del trabajo comunitario participativo para el establecimiento del geoparque mundial de la UNESCO Mixteca Alta, Oaxaca, México, Boletín del Instituto de Geografía UNAM, núm. 92, págs. 1-11, consultado el día 25 de octubre del 2017, disponible en: http://www.scielo.org.mx/ pdf/igeo/n92/2448-7279-igeo-92-00012.pdf 
Sánchez, C. J. L. (2013) "Los geoparques como entes de conservación vinculante: geodiversidad, biodiversidad y patrimonio cultural, Nature and conservation, Vol. 6, núm. 1, págs. 46-53, consultado el día 27 de octubre del 2017, disponible en: https:// www.researchgate.net/publication/319335920_LOS_GEOPARQUES_COMO_ENTES_DE_CONSERVACION_VINCULANTE_GEODIVERSIDAD_ BIODIVERSIDAD_Y_PATRIMŌNIO_CULTURAL_RESUMO_THE_GEOPARKS_AS_BINDING_CONSERVATION_SOURCES_GEODIVERSITY_BIODIVERSITY_AND_CULTURAL_HERITA

Sánchez, C. J. L., Arredondo, G. M. C., Leyva, A. J. C., Ávila, S. G., Figueroa, B. C., Mata, P. J. (2014) "Propuesta de matriz para evaluación de proyectos geoparques en América Latina, con base en áreas naturales protegidas: aplicación y casos de estudio, Pasos Revista de turismo y patrimonio cultural, vol. 12, núm. 2, págs. 383-394, consultado el día 24 de octubre del 2017, disponible en: http://www.pasosonline.org/ Publicados/12214/PS0214_09.pdf

Sandoval, V. D. (2015) "Conservación oficial y extractivismo en México", Centro de Estudios para el Cambio en el Campo Mexicano" CECCAM, consultado el día 24 de octubre del 2017, disponible en: http://ceccam.org/sites/default/files/Extractivismo. pdf

Serrano, F. J. D. P. (2017) Pedagogía social en Colombia: entre la experiencia de la educación popular y el reto de la investigación-acción en la profesionalización socioeducativa de un país en posconflicto, consultado el día 12 de diciembre del 2019, Ensino \& Pesquisa, 15(2), disponible en: http://periodicos.unespar.edu.br/index.php/ ensinoepesquisa/article/view/1644/pdf5

Singer, S. M. (2013) “Justicia electoral. México, participación y representación indígena, Tribunal Electoral del Poder Judicial de la Federación, Temas selectos de Derecho Electoral, núm. 38, consultado el día 24 de octubre del 2014, disponible en: http:// www.trife.gob.mx/sites/default/files/38_justicia.pdf

Schilling, M., Contreras, P., Levy, C. (2015) "Kütralkura: el primer territorio en Chile aspirante a integrarse a la Red Mundial de Geoparques", XIV Congreso Geológico Chileno, octubre, La Serena, consultado el día 25 de octubre del 2017, disponible en: http://biblioteca.sernageomin.cl/opac/DataFiles/14905_v3_pp_431_434.pdf

Torres, M. G., Fernández, M. J. y Gómez, G. C. (2018) "Informe sobre la jurisdicción agraria y los derechos humanos de los pueblos indígenas y campesinos en México", págs. 38-53, Fundación para el Debido Proceso, Washington, Estados Unidos, consultado el día 10 de agosto del 2018.

Van de Velde, H. (2008) Educación popular. Texto de referencia y consulta, Colección: Cuadernos del desarrollo comunitario, $N^{\circ} 3$, Centro de Investigación, Capacitación y Acción Pedagógica (CICAP) y Facultad Regional Multidisciplinaria, (FAREM), Estelí, Nicaragua, 156 Págs. Consultado el día 12 de mayo del 2020. Disponible en: http://abacoenred.com/wp-content/uploads/2016/01/Educacion-Popular-III-ed-HermanVdV-Nicaragua.pdf

Vázquez, O. J. J. (2005) "Conflicto cultural y reconstitución del tejido social: hacia una psicología social de los derechos humanos, promotora de los procesos autonómicos" Iztapalapa Revista de Ciencias Sociales y Humanidades, núm. 59, págs. 69-84, México, consultado el día 4 de agosto del 2018, disponible en: http://www.redalyc.org/ pdf/393/39349210005.pdf

Zmeke de Z, Y. (2000) "La resistencia: forma de vida de las comunidades indígenas", Revista El Cotidiano, vol. 16, núm. 99, págs. 92-102, México, consultado el día 6 de agosto del 2018, disponible en: http://www.redalyc.org/pdf/325/32509909.pdf 
